\title{
A leitura de Monteiro Lobato na contemporaneidade: entre o livro e os quadrinhos
}

\author{
Patrícia Kátia da Costa Pina \\ Universidade Estadual de Santa Cruz / CNPq / Fapesb / Capes
}

\begin{abstract}
RESUMO: ESTE ARTIGO DISCUTE ALGUNS DOS DESAFIOS QUE CERCAM A LEITURA DE LITERATURA, EFETUADA POR CRIANÇAS E JOVENS, NA CONTEMPORANEIDADE, EM FACE DAS NOVAS, DIFERENTES E SEDUTORAS MÍDIAS QUE NOS CERCAM, TENDO COMO OBJETO DE ESTUDO A NARRATIVA LOBATEANA DOM QUIXOTE DAS CRIANÇAS, EM SUA VERSÃO LITERÁRIA E EM HQ. O OBJETIVO É INVESTIGAR COMO A LEITURA DO TEXTO LITERÁRIO, PUBLICADO EM OUTRA MÍDIA QUE NÃO O LIVRO, ENFATIZA O LÚDICO, PODENDO FUNCIONAR COMO FORMA DE APREENSÃO DO MUNDO E CONSTRUÇÃO SIMBÓLICA DE IDENTIDADES.
\end{abstract}

ABSTRACT: THIS ARTICLE DISCUSSES SOME CHALLENGES FACED BY THE ACT OF READING LITERATURE BY CHILDREN AND TEENAGERS, IN THE ADVENT OF SEDUCING AND VARIED NEW MEDIA. THE OBJECT OF STUDY IS LOBATO'S DOM QUIXOTE DAS CRIANÇAS, IN BOTH VERSIONS, LITERARY AND COMIC STRIPS. MY OBJECTIVE IS TO INVESTIGATE HOW THE READING OF LITERARY TEXT PUBLISHED IN A MEDIA OTHER THAN THE BOOK EMPHASIZES THE ACT OF PLAYING, BEING ABLE TO FUNCTION AS MEANS TO APPREHEND THE WORLD AND AS TOOL TO BUILD SYMBOLIC IDENTITY.

PALAVRAS-CHAVE: LEITURA - LITERATURA INFANTIL - HQ - LIVRO KEY-WORDS: READING - CHILDREN'S LITERATURE - COMIC STRIPS - BOOK 
ão nos é possivel penetrar nos textos que lemos, mas estes podem entrar em nós; é isso precisamente o que constitui a leitura." (SCHOLES, 1991: 22)

Esvaziar-se de si e deixar-se preencher pelo Outro - um desconhecido assustador. Isso é LER, com todas as letras maiúsculas. E Scholes, de quem tomo emprestadas as palavras postas em epígrafe, também se refere ao tipo de leitura que, quando ocorre, provoca um deslocamento no sujeito que lê e no mundo que o cerca e com o qual ele interage.

Quando se discute a leitura no Brasil, costuma-se partir de dados numéricos e gerais sobre analfabetismo e de documentos que mostrem as atitudes políticas e administrativas encetadas para que diminua o número de indivíduos que não podem decifrar a escrita. Mas a questão vai além dos índices de alfabetização milagrosamente alcançados por programas governamentais ou particulares. Penso que discutirmos os desafios da leitura hoje implica discutirmos não o número de indivíduos que sabem assinar o nome e votar nas eleições, mas o diminuto quantitativo de indivíduos que ultrapassam os limites da leitura feita apenas com os olhos e mergulham na leitura feita com o coração, a alma, o sangue, a imaginação - essa leitura pode mudar mundos, transformando pessoas.

Esse tipo de leitura, feito por boa parte dos privilegiados universitários e pós-universitários, não deveria ser para tão poucos, deveria ser para todos. É um prazer indescritível o de ler com os olhos da alma - e isso a nossa escola não sabe ensinar, até porque nossos pequenos e cotidianos mestres não souberam ou não puderam aprender. Como ensinar o que não se sabe?

Essa leitura que liberta, que lê o livro, a revista, o jornal, lendo o mundo e a vida, é aquilo a que os acadêmicos de Letras, Educação, Filosofia, História etc., chamam de interpretação. Na escola média, o professor de Língua materna, normalmente responsável pelo ensino de literatura, aplica avaliações em que, supostamente, os estudantes deverão interpretar os textos. Mas essa interpretação, domesticada pelo sistema, não liberta, encarcera. O estudante deverá, nesses casos, adivinhar o que o autor quer dizer, de acordo, claro, com o gabarito do livro didático.

Esse jovem não é convidado a deixar que o texto entre nele e o transforme - ele é obrigado a invadir o território textual, caçando os sentidos prontos que estarão lá, segundo o professor, o diretor e as demais autoridades que se sobre- 
põem à sua própria interação com a obra. Isso não é ler, não é formar leitor, não é formar o gosto pela leitura, não é, ao fim e ao cabo, ensinar literatura e formar cidadãos. A leitura é uma atividade criativa, criadora, aberta. Ela...

[...] tem duas faces e orienta-se para duas direcções distintas, uma das quais visa a fonte e contexto original dos sinais que se decifram, baseando-se a outra na situação textual da pessoa que procede à leitura. Pelo facto de a leitura constituir sempre matéria de, pelo menos, dois tempos, dois locais e duas consciências, a interpretação mantém-se infinitamente fascinante, difícil e essencial. (SCHOLES, 1991: 23)

Assim, a leitura é centrípeta e centrífuga, implica compreender e incorporar. Ler implica interpretar e criticar. As associações que estabelecemos ao ler nos revelam a nós mesmos, nos mostram quem somos no e a partir do texto lido. E se não conseguimos estabelecê-las, por não nos terem sido mostrados os modos de fazer isso, a leitura se torna uma atividade dolorosa, frustrante.

Wolfgang Iser afirma que "Toda interpretación transforma algo em outra cosa." (ISER, 2005: 29). Quando lemos com a alma e com a vida, ou seja, quando interpretamos um texto, nós imaginamos para ele novos sentidos e nos reinventamos nesse processo. A transitividade deve sempre presidir o ato da leitura - ler é interagir com o texto.

Monteiro Lobato, ao conjugar sua vocação pedagógica, empresarial e literária, escrevendo, publicando e vendendo livros para crianças, reagiu à precariedade do mercado livreiro voltado para essa faixa etária no Brasil, precariedade esta histórica, decorrente de nossas práticas culturais desde a Colônia. Segundo Yunes e Pondé,

A questão da leitura, no Brasil, data da época colonial, cujo sistema de dominação impedia que a educação se popularizasse, como forma de manter o povo alienado da informação e do poder. Em conseqüência, o acesso à participação ficava restrito às elites culturais e econômicas, que enviavam seus filhos para estudar na Europa colonizadora. Assim, durante o período colonial inexistia um sistema de difusão cultural, uma vez que a imprensa local era proibida, as raras bibliotecas eram guardadas nos mosteiros e não havia uma massa de leitores que pudesse levar os escritores a modificar seus padrões europeus. Entre 
os intelectuais, educados no exterior, havia uma sensação de desenraizamento, que os impedia de identificar-se com os valores de sua terra natal, senão simbolicamente. (YUNES \& PONDÉ, 1989: 26)

Nossa independência política não construiu do nada, de um ano para outro, uma sociedade caracterizada pela autonomia intelectual. No século XIX brasileiro, ao que parece, independentemente de o escrito circular no livro ou no jornal, sua transformação em moeda cultural de troca cotidiana foi o objetivo comum de toda a nossa elite intelectual. O consumo da cultura impressa tornou-se capital nessa época. Aumentá-lo era prioridade. Para isso, era preciso tornar essa cultura impressa não apenas um instrumento de educação distensa (PINA, 2002), informal: o consumidor educado dentro de determinados padrões passaria a exigir a permanência desses mesmos padrões. Ele teria as marcas dos textos que lhe eram impostos, até porque essa imposição não era explicita.

Escritores, editores e receptores eram partes distintas, mas complementares, do mesmo sistema intelectual, apenas não partilhavam o mesmo saber prévio. Daí, o leitor aparecer como uma construção dos criadores e produtores de bens culturais, daí sua constante introjeção nos textos: buscavam-se estratégias de educação dessa nova espécie cultural

E uma das conseqüências desse processo é que não aprendemos a usar o impresso como mediador de nossas relações sociais até que o século XX chegasse e trouxesse, com suas guerras, as mudanças tecnológicas necessárias para nos empurrar, bastante abruptamente, no mundo letrado. É nesse cenário novecentista turbulento e modernoso que Monteiro Lobato escreve literatura - e lê, publica, divulga, vende livros e revistas. Ele se inscreve na antiga tradição oitocentista de escritores que precisavam construir simbólica e empiricamente seu público leitor. Mas acrescenta às velhas estratégias uma visão empresarial lúcida e eficaz, no que tange à divulgação e circulação do impresso.

$\mathrm{Na}$ apresentação dos volumes $A$ barca de Gleyre, denominada "Escusatória", ele define a literatura como uma atitude, “... a nossa atitude diante desse monstro chamado Público, para o qual o respeito humano nos manda mentir com elegância, arte..." (LOBATO, 1961a: 17). A afirmação, escrita nos primeiros anos do novecentos, dá conta da incômoda situação do escritor: ele se insere nos seus textos, inscreve e reinventa seu mundo e suas expectativas em cada frase que constrói, mas precisa fazer com que essas inscrições che- 
guem a um assustador desconhecido - o leitor. E não apenas isso: ao voltar meu olhar para a epígrafe deste artigo, penso que o escritor é bem mais que um mero anfitrião, que recebe os convivas em sua casa - ao contrário, ele e seu texto invadem a intimidade desse Outro, eles desestabilizam as diferentes alteridades com as quais interagem.

Metaforicamente, arma-se um cabo de guerra, cujas pontas são desiguais, sob quaisquer óticas. A disputa pelo poder da significação textual implica entender que a criação e a recepção de cada obra são processos complementares, mas que se constroem em direções opostas, num desequilíbrio necessário. Monteiro Lobato tem uma visão moderna do livro: para ele, trata-se de uma mercadoria fundamental para o progresso da nação. Escrevendo ao amigo Godofredo Rangel, em 8 de dezembro de 1921, afirma:

O nosso sistema não é esperar que o leitor venha; vamos onde ele está, como o caçador. Perseguimos a caça. Fazemos o livro cair no nariz de todos os possíveis leitores desta terra. Não nos limitamos às capitais, como os velhos editores. Afundamos por quanta biboca existe. (LOBATO, 1961a: 239)

Além de escritor, Monteiro Lobato era dono de editora, então o processo invasivo da leitura se construía, para ele, posso deduzir, de duas formas: de um lado, a invasão do texto, algo íntimo e pessoal; de outro, a invasão do livro, algo material, concreto, visível. Essa percepção da cultura como mercado de circulação de bens conjuga economia, pedagogia e literatura. Explico: vendo o leitor como objeto de caça, ele precisa armar-se de todos os instrumentos necessários para atingir a presa. Assim, é preciso ter um objeto concreto para chamar-lhe a atenção - o livro. Esse objeto não pode ser atrativo apenas aparentemente, pois isso significaria vendê-lo apenas uma vez. Cada livro publicado, conseqüentemente, precisa ter atrativos internos, pertinentes à composição literária e à própria composição da página. Para finalizar, o livro deveria ser preparado para formar hábitos de consumo e padrões de gosto, capazes de agradar ao segmento do leitorado ao qual se dirigiria. Idéias novecentistas herdadas de um processo oitocentista de construção utópica, simbólica e frustrada do leitorado brasileiro.

Sua visão do impresso é típica do início do século XX. Como empresário que dependia duplamente do mercado, Lobato parece se propor a criar seg- 
mentos específicos e fiéis de consumidores para os bens culturais que produzia, como afirma ao mesmo amigo, em maio de 1926:

Ando com idéias de entrar por esse caminho: livros para crianças. De escrever para marmanjos já me enjoei. Bichos sem graça. Mas para as crianças, um livro é todo um mundo. [...]. Ainda acabo fazendo livros onde as nossas crianças possam morar. Não ler e jogar fora; sim morar... (LOBATO, 1961a: 293)

O bom é que ele associa ao projeto empresarial o projeto pedagógico e literário de formar bons leitores. A leitura, na ótica de Lobato, parece agregar aos valores maiores para o Brasil novecentista burguês - conhecimento e renda - um valor diferenciado e que, em se tratando de processos educativos, era visto com desconfiança e preconceito - o valor da imaginação, do lúdico, da aprendizagem como diversão, como jogo. Johan Huizinga trabalha com a importância do jogo na vida social:

As grandes atividades arquetípicas da sociedade humana são, desde início, inteiramente marcadas pelo jogo. Como por exemplo, no caso da linguagem, esse primeiro e supremo instrumento que o homem forjou a fim de poder comunicar, ensinar e comandar. É a linguagem que lhe permite distinguir as coisas, defini-las e constatá-las, em resumo, designá-las e com essa designação elevá-las ao domínio do espírito. Na criação da fala e da linguagem, brincando com essa maravilhosa faculdade de designar, é como se o espírito estivesse constantemente saltando entre a matéria e as coisas pensadas. Por detrás de toda expressão abstrata se oculta uma metáfora, e toda metáfora é jogo de palavras. Assim, ao dar expressão à vida, o homem cria um outro mundo, um mundo poético, ao lado do da natureza. (HUIZINGA, 2001: 7)

Para fazer as crianças morarem nos livros, Lobato precisaria jogar com elas: ele cria, então, um mundo à parte, um mundo mágico, composto de aventuras fantásticas. Lendo a obra infantil lobatiana pelo conceito de jogo trazido por Huizinga, é possível pensar que a tensão que preside o jogo é que funcionaria como instrumento de provocação e de "sedução" dos pequenos leitores. Essa tensão, no âmbito do literário, preside o ato interpretativo. 
Uma das formas de instrumentalizar essa tensão e torná-la eficaz para seduzir a criança leitora ou ouvinte de suas histórias é a adaptação lúdica de narrativas pertencentes ao nicho reservado à alta literatura, como ocorre com o Dom Quixote, de Cervantes. Entendo, nesse contexto de reflexão, que adaptar é fazer uma leitura interpretativa prévia.

No início do D. Quixote das crianças, Emília, personagem mais sedutora da ficção infantil de Monteiro Lobato, envolve o pobre Visconde de Sabugosa em mais uma de suas peraltices. Dona Benta arrumava a estante de livros, colocando nas prateleiras mais baixas os que supunha - com base em critérios de valor não explicitados, mas facilmente identificáveis como aqueles que regem a formação do cânone literário ocidental - serem de melhor compreensão para os meninos e, nas mais altas, aqueles que leriam quando tivessem habilidades para isso. A boneca, insubordinada e irrequieta, quer exatamente os que estão nas prateleiras mais altas.

Simbolicamente, a ordem dos livros no Sítio representa o poder do impresso, isto é, representa a força da palavra concreta sobre aqueles que estão além da página. Insatisfeita, Emília convoca, então, o Visconde para auxiliá-la numa desobediência: ela quer ajuda para pegar uns volumes grossos e grandes:

Emília estava na sala de Dona Benta, mexendo nos livros. Seu gosto era descobrir novidades - livros de figura. Mas como fosse muito pequenina, só alcançava os da prateleira debaixo. Para alcançar os da segunda, tinha de trepar numa cadeira. E os da terceira e quarta, esses ela via com os olhos e lambia com a testa. Por isso mesmo eram os que mais a interessavam. Sobretudo uns enormes. (LOBATO, 1967: 12)

Emília não aceita apenas contemplar a obra, vê-la à distância - para ela, vivenciar o lido é fundamental. Essa arrumação física dos livros não a impediu de tomar o volume que lhe interessava, com o socorro do sabugo de milho falante. Este, no entanto, foi quem mais sofreu com a desordem instalada pela boneca que, ao pegar Dom Quixote, deixa-o cair e esmaga o Visconde. O desejo impositivo de Emília quase custa a vida de seu "sogro". Tudo por querer ler aquilo que the estava vetado.

Dona Benta, então, na tentativa de saciar sua curiosidade dela e dos meninos, se propõe a fazer uma leitura seletiva da obra, na verdade, a fazer uma 
interpretação das histórias de D. Quixote e Sancho Pança. Marisa Lajolo, estudando o livro Histórias de Tia Nastácia, aponta que

[...] a oralidade se manifesta estruturalmente também em outras obras de Lobato, nas quais o escritor recorre à moldura da narração oral, como D. Quixote das crianças e Peter Pan. Nestes livros, porém, o recurso à oralidade constitui estratégia adotada por Dona Benta [...] para facilitar o ingresso das crianças - ouvintes no mundo da leitura. Ou seja, em D. Quixote das crianças e em Peter Pan, se a enunciação mimetiza o mundo da oralidade, o enunciado vem do moderno mundo da escrita, ao qual se subordina o da oralidade, mero instrumento de passagem deste para aquele. (LAJOLO, 2008: 71)

Lobato dialoga com nossa tradição colonial: ele sabe que ler, na sociedade brasileira, foi sempre um luxo, e ele brinca com as fronteiras desse objeto de distinção social, que é o livro. A escrita detém o poder e o acesso ao livro implica a partilha desse poder. A mediação necessária de Dona Benta enfatiza a distância que o mundo da escrita e do impresso ainda guarda em relação ao auditório composto pelos meninos, pela cozinheira e pelos bonecos. A princípio, ela tenta ler o livro, mas o auditório reclama da linguagem, ao que ela retruca:

- Meus filhos - disse Dona Benta - esta obra está escrita em alto estilo, rico de todas as perfeições e sutilezas de forma, razão pela qual se tornou clássica. Mas como vocês ainda não têm a necessária cultura para compreender as belezas da forma literária, em vez de ler vou contar a história com palavras minhas. (LOBATO, 1967: 17)

Talvez de forma bastante crítica, Lobato metaforize, aí, a ação dos escritores e demais intelectuais, no que tange à divulgação da cultura impressa: ele facilita o acesso ao livro. No Brasil do primeiro novecentos, ainda eram poucos os que podiam ter em mãos os grandes livros da humanidade. Dona Benta tinha, era uma senhora culta, versada em diferentes assuntos. E esse saber erudito dava-lhe uma autoridade mascarada sobre os netos e os demais habitantes das páginas lobatianas, bem como sobre a criança que se debruçasse sobre a obra em questão.

Se, por um lado, ela relativiza a simbólica arrumação da estante e cede aos desejos dos netos e da boneca, ao adaptar o livro para seu auditório, por 
outro, coloca todos em seus lugares, apontando a necessidade da mediação, por não terem os interlocutores o repertório que lhes permitiria compreender o livro e ressaltando, de forma indireta, a relevância de uma assimetria entre leitores comuns, leitores "preparados" e obra, implicitamente definindo o ato da leitura como uma atividade adequada apenas a iniciados.

A vantagem é que sua intervenção é lúdica e interativa: Dona Benta interpreta, na verdade, o que lê. Essa interpretação é passada aos netos e aos demais ouvintes. Embora a associação entre leitura, interpretação e poder fique clara, através das intervenções das crianças e das diferentes formas de apropriação das histórias representadas no livro, ressalta nesse processo a viabilização de certa liberdade imaginária.

Essa associação é reinventada na adaptação do livro de Lobato para os quadrinhos, empreendida pela Editora Globo. Os desenhos fazem uma apresentação direta do que poderia ser imaginado pelo leitor de Monteiro Lobato: as cores, o tamanho das imagens, os balões, todos esses recursos concretizam o que, no livro novecentista, era pura provocação ao leitor.

A introdução do volume é feita por um texto assinado por Emília: ali, a boneca é representada com uma bacia velha na cabeça, uma vassoura numa das mãos e algo como um prato na outra, numa antecipação da cena em que a boneca vai para o quintal brincar de ser Dom Quixote. Ela é posta na parte inferior da página e, à exceção do título ("Aventuras Quixotescas"), impresso em marrom, com letras um pouco desarrumadas, é o único toque de cor. Certamente, sua imagem desvia o olhar da criança do texto, esvaziando, um pouco, a importância da palavra impressa. Mas, como toda moeda tem duas faces, esse desvio pode ser já uma isca para prender a atenção do leitor.

Se a criança resolver se debruçar pelo estafante texto de uma página, deparar-se-á com referências a várias aventuras vividas nas narrativas de Lobato, num processo de intertextualização bastante provocante. E mais, encontrará explícito o objetivo da transformação da narrativa verbal em narrativa que mistura o visual ao verbal, com amplo privilégio para o primeiro: Emília afirma que o objetivo de fazer o livro em quadrinhos foi aumentar o número de pessoas que teriam acesso às aventuras do Cavaleiro da Mancha. Talvez possamos retomar o sonho de Lobato - aquele de fazer as crianças morarem nos livros. Vejo, aí, um desdobramento das preocupações e das estratégias do empresário-pedagogo-escritor de Taubaté: a leitura deve ser para muitos, não 
para pequenos grupos privilegiados. Nesse ponto, os editores acertaram em cheio. Em outros também.

A primeira página dos quadrinhos reproduz a cena em que Emília quer pegar o livro no alto da estante. Vários recursos gráficos são usados para direcionar o olhar da criança para os pontos importantes da página: as prateleiras mais baixas trazem livros de cores frias: cinza, bege, marrom, amarelo. $\mathrm{Na}$ última prateleira, explode um grosso livro vermelho, com letras amarelas enormes. Na mesma prateleira, dando início à carreira de livros, em azul, também com letras amarelas, Urupês, numa referência à relevância do criador da bonequinha de macela.

O livro de Cervantes é maior que Emília. Ela não consegue suportar seu peso e o deixa cair em cima do Visconde. Na obra de Lobato, o leitor é convidado a ver, em seu teatro mental, a cena. Nos quadrinhos, a cena lhe é dada: o pobre sabugo jaz esmagado pela força da ficção. E o caldinho da ciência, que Emília recolhe, após levantarem do chão o que restou do Visconde, aparece bem verdinho aos olhos da criança que folheia o livro.

$\mathrm{Na}$ seqüência da narrativa em quadrinhos, conforme a história de Cervantes vai sendo contada por Dona Benta, suas personagens são vividas pelas personagens do Sítio. Dom Quixote assemelha-se intimamente ao Visconde, por exemplo. Interessante, também, é a supressão de Sancho Pança em algumas aventuras iniciais, ao contrário do original e da adaptação lobatiana. Quando aparece, Sancho é representado por Rabicó - associação interessante e divertida para o pequeno leitor.

Efetivamente, os quadrinhos invadem o universo do leitor. A tensão por eles criada, se, de um lado, pode amortecer a capacidade imaginativa do desejado interlocutor, de outro, penso que pode instigá-la, principalmente se os quadrinhos não forem lidos como único referencial para a interação da obra lobatiana com o leitorado infantil. Eles promovem, sim, uma ampla facilitação do lido, por concretizarem, no papel impresso, uma leitura já feita. Mas, também, permitem que a criança se identifique mais intensamente com as personagens e suas ações. Trata-se de uma terceira adaptação da obra de Cervantes, feita não a partir do original, mas da adaptação anterior. Claro que não é um processo ideal, mas pode dar bons resultados. Basta que se pense como o próprio Monteiro Lobato, que queria fazer da literatura a casa das crianças e dos adultos. A representação visual é uma alternativa muito interessante nesse sentido. 
A criança que lê os quadrinhos toma conhecimento de uma história adaptada, a partir de uma adaptação primeira, ou seja, ela é conduzida pelo olhar de um Outro, ainda mais superior a ela que Dona Benta aos netos e bonecos. Mas o jogo instaurado pelos quadrinhos pode convidá-la a sair do circuito da visualidade e a entrar no campo da palavra, da imagem verbal. E a própria visualidade pode permitir-lhe reinventar o lido e reinventar-se a partir do lido.

As novas mídias, dentre as quais a TV, o cinema, os quadrinhos, entram no circuito da formação do gosto pela leitura literária construindo um espaço paradoxal, mas eficiente. Elas jogam com nossa tradição de oralidade, como o escritor de Taubaté jogou, ao tornar a linguagem literária menos formal e mais próxima do cotidiano dos pequenos leitores. Jogam, também, com as expectativas de diferentes grupos leitores, confrontando as imagens construídas pelas variadas linguagens. Elas revelam, pelo apelo da cor, da forma, da concretude imagística, a criança a si mesma e ao seu Outro maior e mais poderoso - o adulto, seja o pai, a mãe, o professor.

Os quadrinhos invadem a criança e deixam-se invadir por ela, estabelecendo caminhos alternativos, lúdicos, de ler a ficção, o mundo e a si mesmo no mundo.

\section{Referências Bibliográficas}

HUIZINGA, Johan. Homo ludens: o jogo como elemento da cultura. Trad. João Paulo Monteiro. 5. ed. São Paulo: Perspectiva, 2001.

ISER, Wolfgang. Rutas de la interpretación. Trad. Ricardo Rubio Ruiz. México: FCE, 2005.

LAJOLO, Marisa. Linguagens na e da Literatura Infantil de Monteiro Lobato. In: ; CECCANTINI, João Luís (Org.). Monteiro Lobato livro a livro: obra infantil. São

Paulo: Ed. Unesp; Imprensa Oficial do Estado de São Paulo, 2008, p. 15-29.

LOBATO, Monteiro. A barca de Gleyre. 10. ed. São Paulo: Brasiliense, 1961a, $2^{\circ}$ Tomo.

. Cartas escolbidas. 10. ed. São Paulo: Brasiliense, 1961b. $2^{\circ}$ Tomo.

. Dom Quixote das crianças. 9. ed. São Paulo: Brasiliense, 1967.

Dom Quixote das crianças. São Paulo: Globo, 2007. [Monteiro Lobato em quadrinhos]

PINA, Patrícia Kátia da Costa. Literatura e jornalismo no oitocentos brasileiro. Ilhéus: Editus, 2002. 
SCHOLES, Robert. Protocolos de leitura. Trad. Lígia Guterres. Lisboa: Edições 70, 1991.

YUNES, Eliana; PONDÉ, Glória. Leitura e leituras da literatura infantil. 2. ed. São Paulo: FTD, 1989. 